\title{
AGRICULTURAL DROUGHT AND SOIL MOISTURE ANALYSIS USING SATELLITE IMAGE BASED INDICES
}

\author{
S. Sreekesh ${ }^{1 *}$, Navneet Kaur ${ }^{1}$, Sreerama Naik S. R ${ }^{1}$. \\ (sreekesh@mail.jnu.ac.in, navneetchandi95@gmail.com, shree.rathod72@gmail.com) \\ ${ }^{1}$ CSRD, Jawaharlal Nehru University, New Delhi
}

Commission III, WG III/10

KEY WORDS: Drought, Standard Precipitation Index, NDVI, Vegetation Health Index, Temperature Vegetation Dryness Index

\begin{abstract}
:
The deficiency in rainfall leads to meteorological droughts. Its manifestations are visible both in the vegetation cover and soil moisture. The present study assessed the characteristics of agricultural drought following meteorological droughts. The study also assessed the severity of meteorological droughts and their manifestation on the agriculture and soil moisture in a semi-arid area. The study has been carried out for the Malaprabha sub-basin which partly covers three districts of North Interior Karnataka, India. India Meteorological Department's (IMD) criteria have been used to identify the drought years, and its severity has been assessed through the Standard Precipitation Index (SPI). The IMD's monthly rainfall data were used to identify the drought years and periods for the region. Among the drought years, the mild, moderate, and severe drought along with deficit and excess rainfall years were considered to assess and characterize the soil moisture conditions and the agricultural drought. The satellite image based indices for these selected years were constructed to determine the soil moisture conditions and the agricultural drought severity. The Temperature-Vegetation Dryness Index (TVDI) was used to determine the soil moisture conditions. The indices employed to determine the agriculture drought are NDVI, Thermal Condition Index (TCI), Vegetation Condition Index (VCI), and Vegetation Health Index (VHI). These satellite-based indices were calculated using the Landsat images of the selected drought and non-drought years. The results showed that the seasonal and annual drought are frequent in the study area. There are spatial and temporal variations in the drought years and their severity. The satellite-based indices clearly indicate the spatial variation in the agriculture droughts and its intensity. It has been found that the impact of drought on agriculture has significantly reduced due to the development of well-irrigation in the sub-basin. VHI is more appropriate in determining the agricultural drought and its characteristics.
\end{abstract}

\section{INTRODUCTION}

Drought is a natural climatological phenomenon due to deficit rainfall than the normal received in an area. In the context of agriculture, it manifests in the form of inadequate supply of water to meet crop water requirements either from rainfall or irrigation. Once there is a negative departure of rainfall from the normal, drought begins to manifest initially in the form of soil moisture deficiency and consequently as vegetation stress leading to its wilting. Drought has spatial and temporal manifestations (Mallya et al., 2015). It is imperative to understand the spatial manifestation of drought and its effect on soil moisture and crops to ensure food security and also sustainable cropping activities through crop insurances. The proper assessment of annual and seasonal droughts is essential for developing a drought information system for crop management. Several studies have developed indices to assess the magnitude, duration, and spatial extent of droughts (Mishra and Singh, 2010; Zargar et al., 2011).

The intensity and extent of drought depend upon the climatic characteristics of the region ( Svoboda et al., 2012) along with the magnitude of rainfall deficiency and antecedent moisture conditions of the soil (Waseem et al., 2016). The indices are used to identify and characterize the droughts (Zargar et al., 2011). Earlier indices such as the Palmer drought severity index (Palmer, 1965), Bhalme and Mooly drought index (Bhalme and Mooley, 1980), standard precipitation index (McKee et al., 1993,
1995) and a more recent index, standardized precipitation evapotranspiration index (Vicente-Serrano et al., 2010), used either a single or combination of climatic elements to identify and quantify the drought characteristics. Use of these indices is limited by the availability of climate data for a reasonable period in the vicinity of the area of interest. These limitations are surpassed by the advent of optical satellite remote sensing wherein periodic satellite images are available to continuously monitor the drought initiation and progression. First noticeable manifestation of drought in vegetation is found in agricultural crops, wherein the health of crop deteriorates consequential to the reduced photosynthetic activity, which is easily captured in multispectral satellite images. Thus, satellite remote sensing has been extensively used for assessing these agriculture water stresses and droughts ( Rojas, 2011; Basso et al., 2004; Sholihah et al., 2016). Drought monitoring can also be carried out by using satellite images and by deriving appropriate indices (Gouveia et al., 2017; Kogan, 1997; Vicente-Serrano et al., 2015). The advantage of satellite remote sensing is that drought can be identified and assessed well in advance than it is identified through conventional methods. Drought intensifies as and when high atmospheric temperature concurrently prevails with low soil moisture conditions. In such situations, the vegetation health due to atmospheric temperature can be effectively analyzed using satellite images. There are many satellite-based agriculture drought assessment indices that are developed based on the satellite remote sensing. The vegetation health index (VHI) is the

\footnotetext{
Corresponding author
} 
most widely used satellite image-based index for drought monitoring and characterization (Bento et al., 2018).

This paper assessed the agricultural drought and soil moisture conditions in a tropical river catchment under different meteorological drought conditions. It also examined how the severity of the drought is offset by the improvement in water harvesting and irrigation infrastructure. The study also explored the use of satellite remote sensing based soil moisture and drought indices for this purpose.

\section{MATERIALS AND METHODS}

\subsection{Study area}

The study was carried out in the Malaprabha sub-basin of the river Krishna, located in the North Interior Karnataka meteorological subdivision. The major area of sub-basin lies in Belgaum, and small portions in Gadag and Bagalkot districts (Figure 1). The region experiences hot and humid climate. The western part of the basin, located in the Western Ghats, is more humid than the eastern part, which is dry. March to May is the summer season, and April experiences the highest maximum temperature. June to September is the monsoon season while October and November is the post-monsoon season. December to February is the winter season and December has the lowest minimum temperature. The average annual maximum and minimum temperatures are about $33^{\circ}$ and $19^{\circ} \mathrm{C}$, respectively. The normal annual rainfall of the Belgaum meteorological station, which is the nearest to the Malaprabha sub-basin, is $1339 \mathrm{~mm}$ out of which 77.8 per cent is received during monsoon season while 11.5 per cent during post-monsoon season. The remaining rainfall is received during the summer months since winter (January-February) rainfall is absent in this region.

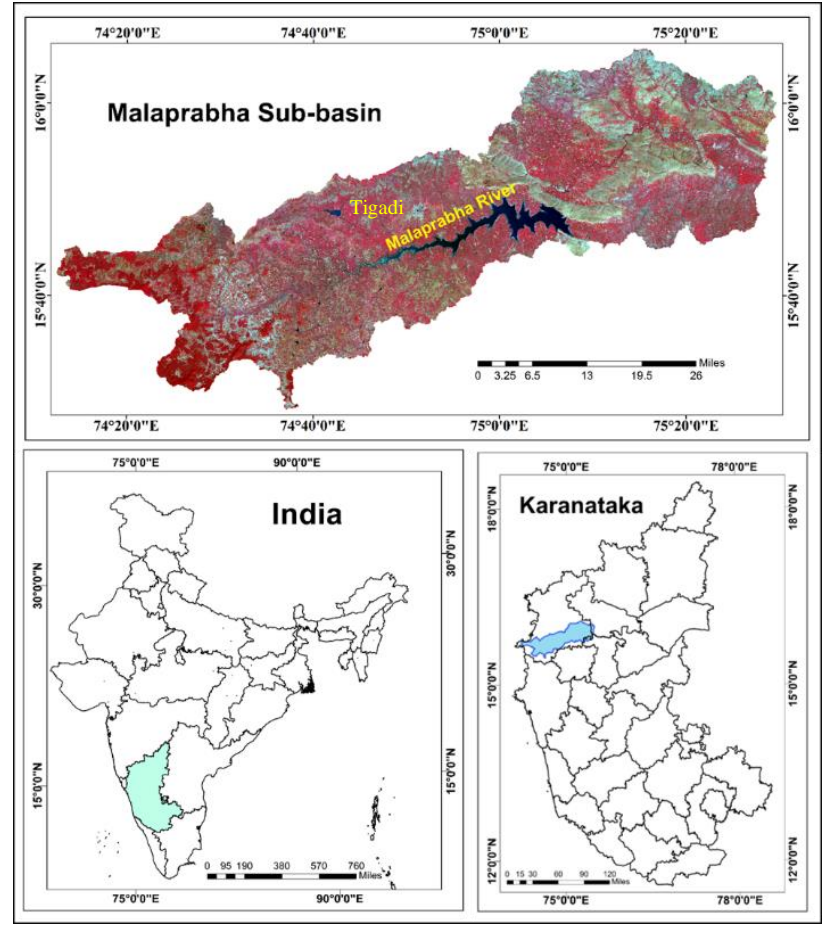

Figure 1. Location of Malaprabha sub-basin

The watershed covers an area of 3719.25 sq. km. The Dharwar series is the main rock type in the sub-basin. The area has predominantly shallow to very deep black soil along with red and sandy soils (CGWB, 2007). The laterite soils are common, especially towards the eastern part of the basin. The western part of the sub-basin is predominantly covered with evergreen and deciduous forests. There are three distinct cropping seasons, namely Kharif (April to September), Rabi (October to December) and Summer (January to March). Major cereal crops grown in this area are paddy, wheat, jowar, bajra, maize, sunflower, etc. and the cash crops grown are sugarcane, cotton, groundnut, soybean and tobacco (Census of India, 2011).

\subsection{Data}

2.2.1 Rainfall: The rainfall data for Belgaum and Gadag stations were obtained from India Meteorological Department (IMD), Pune for the period 1990 - 2017 for the identification of the drought years.

2.2.2 Satellite images: The study made of images of Landsat satellite's series of sensors (TM, ETM+, OLI, and TIRS) which has been procured from the United States Geological Survey (USGS), Earth Resources Observation and Science (EROS) Centre archives. The digital image analysis was carried out with estimated surface spectral reflectance of red and infrared bands of Landsat, which were already corrected (level 2) for geometric and atmospheric distortions (Masek et al., 2006) while thermal images (level 1) were subjected to atmospheric corrections following Sobrino et al. (2008) and Chander et al. (2009) before calculating the indices $\mathrm{s}$ for drought assessment. The satellite images were selected for the winter season since it is the period of the initial manifestation of drought in the study area. Besides, January and February are likely to have cloud-free atmospheric conditions that ensure good quality images.

\subsection{Methods}

The drought and its periods were assessed based on monthly rainfall data while the agriculture drought, status of soil moisture, and the vegetation health were studied using satellite images of the selected years.

2.3.1 Meteorological Drought Identification: Droughts were identified based on the IMD criteria. Accordingly, a season or year is considered to be a drought if the percentage departure of realized rainfall from normal rainfall is less than -19\% (IMD, undated). The drought years were identified based on the departure of annual rainfall from the normal (for 1961-1990 period) rainfall. The monsoon and post-monsoon seasonal rainfall departures from their respective normal were also calculated to explain the variation in vegetation cover and water spread during drought years. The intensities of droughts were determined using the SPI values following McKee et al. (1993). SPI estimates a standardized departure of actual rainfall with respect to rainfall probability distribution function. Hence this drought indicator enables the comparison of droughts across space and time. A detailed discussion on the method of identification of drought intensity can be found in McKee et al. (1993).

The annual SPI values are calculated for assessing long term drought persistence in the study area (Zargar et al., 2011). In addition, the monsoon and post-monsoon seasons SPI values are also calculated to ascertain the influence of seasonal SPI values on vegetation condition and the status of drought during the periods of satellite image analysis. Thus, in addition to annual SPI values, seasonal SPI values are also considered while selecting the years for image analysis. The positive SPI value 
indicates non-drought periods while negative SPI values indicate the drought periods. The annual, monsoon and post-monsoon SPI values were calculated for the period 1990-2017 using annual and monthly rainfall data of IMD station in Belgaum district. The drought severity classification scheme of McKee et al. (1993) modified by Doesken and Kleist (1993) was used to classify SPI values (Table 1). The annual SPI values, along with the monsoon and post-monsoon SPI values, were used to select the years for agricultural drought and soil moisture assessment. The satellite images were selected for the months after the post-monsoon season (that is January-February), which falls in the next calendar year.

Table 1. Intensity classification of SPI values

\begin{tabular}{lc}
\hline Drought intensity classes & SPI Ranges \\
\hline Extremely dry & -2 and less \\
Severely dry & -1.5 to -1.99 \\
Moderately dry & -1.0 to -1.49 \\
Mild drought & $<0$ to -0.99 \\
Mild wet & $>0$ to 0.99 \\
Moderately wet & 1.0 to 1.49 \\
Very wet & 1.5 to 1.99 \\
Extremely wet & $2.0+$ \\
\hline
\end{tabular}

2.3.2 Soil moisture assessment: The soil moisture status regulates the initiation of drought and its progression. The deficit soil moisture is a good indicator of agriculture drought and intensity (Sheffield, 2004; Vyas, 2015). At high-temperature conditions, the soil moisture quickly depletes, leading to drought and wilting of vegetation. There is a direct relationship between soil moisture and vegetation vigour, which is easily assessable using satellite images. The vegetation-land surface temperature (LST) relationship was first determined as an index of crop water stress by Moran et al. (1994) through field experimental study which was further modified by Sandholt et al. (2002). They identified a triangular space showing the relation of LST with NDVI to develop a regression equation to determine the soil moisture using satellite images. In this study, following Sandholt et al. (2002), the soil moisture was assessed using temperaturevegetation dryness index (TVDI), which indicates relative presence or absence of moisture in the soil.

$$
T V D I=\frac{L S T-L S T_{\min }}{L S T_{\max }-L S T_{\min }}
$$

where $\mathrm{LST}=$ land surface temperature values for a given year $\mathrm{LST}_{\min }$ and $\mathrm{LST}_{\max }=$ minimum and maximum land surface temperature values for a given year.

The TVDI values range from 0 to 1 , and values near to zero indicate soil wetness while it approaches to 1 the soil is near to absolute dryness.

2.3.3 Vegetation Health Index (VHI): The effect of meteorological drought over large areas can be assessed based on the health of the vegetation (Sholihah et al., 2016). The health of the vegetation was determined by the vigour of photosynthetic activity, which depends upon the availability of moisture in the soil and insolation conditions. This can be captured in satellite remote sensing and VHI facilitate the determination of phonological characteristics of vegetation (Kogan, 1987). VHI, a function of vegetation condition index (VCI) (Kogan, 1994) and temperature condition index (TCI), indicates the vegetation health or stress (Kogan, 2002). The VCI, computed from normalized difference vegetation index (NDVI) values, indicates the effect of moisture on vegetation while the TCI is a function of the LST. Based on the TCI values, temperature related vegetation stress, as well as stress due to excessive wetness, can be retrieved (Singh et al., 2003). These indices are computed using the following equations.

$$
V C I=\frac{N D V I-N D V I_{\min }}{N D V I_{\max }-N D V I_{\min }} * 100
$$

where $\quad$ NDVI $=$ NDVI values for a given year

$\mathrm{NDVI}_{\min }$ and $\mathrm{NDVI}_{\max }=$ minimum and maximum NDVI values for a given year

The NDVI is an indicator of vegetation phenology that captures the seasonal dynamics of vegetation (Wang et al., 2017). As the VCI values increase from lower to higher, the vegetation condition improves from poor to optimal (Singh et al., 2003). However, VCI alone is not good enough to determine the extent and intensity of drought. The intensity of drought not only contingent on the deficiency of rainfall but also a function of soil moisture and surface temperature conditions, which in turn rest on air temperature. In order to capture these effects, the TCI was calculated.

$$
T C I=\frac{L S T_{\max }-L S T}{L S T_{\max }+L S T_{\min }} * 100
$$

where $\quad$ LST $=$ LST values for a given year $\mathrm{LST}_{\min }$ and $\mathrm{LST}_{\max }=$ minimum and maximum LST values for a given year

The $\mathrm{LST}_{\min }$ in an area is indicative of the presence of moisture in the soil and thus relative vegetation or crop health while LST $\max$ indicates the thermal stress that leads to water deficit conditions and consequent vegetation or crop stress.

VHI is resultant of the additive function of VCI and TCI with a coefficient of proportionality for each.

$$
V H I=\alpha V C I+(1-\alpha) T C I
$$

where $\alpha=$ coefficient indicating the proportion of VCI and TCI.

In this study, ' $\alpha$ ' coefficient was assumed to be 0.5 , since the role of moisture and temperature is equal in determining the vegetation health. In addition, in the present study area, the crop and other vegetation growth cycles are different. In regions where crop and other vegetation growth cycles are different, an equal weight is assumed for VCI and TCI (Kogan, 2001).

2.3.4 Drought Intensity Classification: Based on the VHI values, the drought intensity was assessed. VHI values less than 40 were considered as drought area whereas, above that, it is healthy vegetation. Further, the drought areas ( $<40$ VHI values) were categorized into mild (30-40), moderate (20-30), severe $(10-20)$ and extreme $(<10)$ drought regions (Kogan, 2002). The area estimates were also attempted to understand the spatial extent of these drought severity categories as well as for nondrought areas. The non-drought areas are forest, agriculture areas, or water bodies. The VHI values will be lower for water bodies, similar to drought areas since both NDVI and LST values are low in areas covered by water. In order to overcome this problem, normalized difference water index (NDWI) was calculated to extract the water bodies (McFeeters, 1996) using bands in near-infrared and green wavelengths. NDWI image was used to substitute water submerged areas which were wrongly classified as drought. 


\section{ANALYSIS AND DISCUSSION}

The analysis of the effect of meteorological drought on soil moisture and agriculture is a three-stage process in which initially drought years and its intensity is determined following the methods discussed above. Subsequently, the soil moisture and the vegetation health status are determined using satellite images of red, infrared, and thermal regions.

\subsection{Drought and Its Intensity}

The drought analysis, based on the IMD criteria, found that 14 out of 28 years were drought years during 1990-2017. Among the drought years identified 2 were mild, 10 moderate and 2 severe. All most all (12) the droughts occurred after the year 2000. It points to the role of global warming on the incidence of droughts since 16 of the 17 warmest years occurred post year 2000 (WMO, 2018). The incidence of moderate drought is more frequent in the study area every one year out of three were drought year since 1990. In addition, 8 years experienced deficit rainfall than the normal. Only 5 years had positive rainfall departure from the normal, out of which 3 years had excess rainfall. These excess rainfall years were prior to 1998 .

The results were cross-examined with SPI values for the study period. According to SPI values, 21 years were under different intensities of drought. The analysis of the intensity of the drought found that there were 5,7 , and 9 years of severe, moderate, and mild drought, respectively (Table 2 ). The years of mild drought as per SPI values coincide with the mild and deficit rainfall years as per the IMD criteria while moderate and severe drought years were in concurrence except in 2003, 2013, and 2016 during which, severe drought was experienced according to SPI values rather moderate as per IMD criteria. There is a general agreement in drought years as per IMD criteria and SPI values. However, the drought severity is better captured through SPI values rather than IMD criteria. Moreover, a more precise index of drought can be obtained from SPI, which is useful for spatial and temporal comparison of drought intensities.

Table 2. Years of drought intensity classification based on SPI values

\begin{tabular}{cccccccc}
\hline $\begin{array}{c}\text { Severe } \\
\text { Drought }\end{array}$ & \multicolumn{3}{c}{$\begin{array}{c}\text { Mod. } \\
\text { Drought }\end{array}$} & SPI & $\begin{array}{c}\text { Mild } \\
\text { Drought }\end{array}$ & SPI & $\begin{array}{l}\text { Non } \\
\text { Drought }\end{array}$ \\
\hline 2003 & -1.57 & 1995 & -1.27 & 1990 & -0.29 & 1991 & 1.25 \\
2012 & -1.68 & 1999 & -1.02 & 1996 & -0.43 & 1992 & 1.52 \\
2013 & -1.52 & 2001 & -1.25 & 1998 & -0.64 & 1993 & 0.59 \\
2015 & -1.67 & 2007 & -1.16 & 2000 & -0.48 & 1994 & 1.49 \\
2016 & -1.60 & 2008 & -1.48 & 2002 & -0.57 & 1997 & 0.91 \\
& & 2014 & -1.07 & 2004 & -0.38 & 2009 & 0.02 \\
& 2017 & -1.41 & 2005 & -0.30 & & \\
& & & & 2006 & -0.95 & & \\
& & & & 2010 & -0.98 & & \\
\hline
\end{tabular}

The soil moisture and agriculture drought were assessed for the meteorological drought years. The analysis was carried out for selected years based on the SPI values. The one year each was selected for mild, moderate, and severe drought years and also for a non-drought year. The year with highest annual SPI value (table 2) from each drought and non-drought classes was a candidate for the analysis of agriculture drought and soil moisture assessment. In addition, in the case of drought years, the monsoon and post-monsoon SPI values should also be negative. On the basis of these two criteria, years 2012 (severe), 2017 (moderate), 2006 (mild) and 1994 (non-drought) were selected to understand the agriculture drought and soil moisture status. Accordingly, as discussed in 2.3.1., the cloud-free images of either January or February were analyzed for 2013, 2018, 2007 and 1995 respectively for severe, moderate, mild, and nondrought years.

\subsection{Soil Moisture Status}

The status of soil moisture and consequent status of agriculture drought during different meteorological drought years was assessed using satellite image-based indices. The analysis of the satellite images for different intensities of meteorological drought and non-drought years has shown that the TVDI ranged from 0 to 0.98 in the study area (Figure 2). Majority of the study area generally had low soil moisture conditions during the assessment period. It is a signpost of drought proneness of the sub-basin. Spatially higher reaches of the sub-basin had low moisture conditions. These were area devoid of vegetation. In general, there is a close relationship between intensities of meteorological drought and TVDI values. However, in those part of the sub-basin where irrigation water is available, the impact of meteorological drought was either absent or minimal.

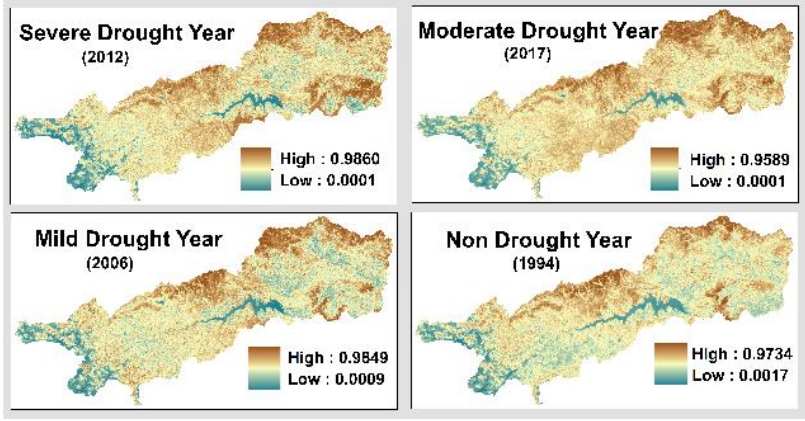

Figure 2. TVDI variation, indicative of the soil moisture conditions under different drought intensity conditions.

Lower TVDI values, indicative of good soil moisture, are noticed in the forest and water covered areas while the high values were in and around the barren lands. The higher TVDI values are always found near to the ridges, along the moderate to steep sloping areas or in laterite soils. During the drought years, the TVDI values were as high as 0.98 for these areas. The maximum TVDI values during 2017 (moderate drought year) were only 0.95 , indicating marginally better moisture conditions in comparison with the mild and non-drought years. This is mainly due to the improved water availability for irrigation from a large number of reservoirs and energized tubewells that sprang up in this area during the latter part of the assessment period. The effect of mild drought was analyzed for the year 2006, during which the water availability for irrigation was less (Figure 3). Consequently, soil moisture conditions were lower, even in a cultivated area. On the other hand, during 1994, the non-drought year selected for the present study, the irrigation infrastructure, and water availability was least. A major dam, Tigadi (Figure 1), was commissioned in the year 2001, which improved the irrigation potential in the upper Malaprabha sub-basin. During the period 1999-2016, the net irrigated area has grown by 30.5 per cent in the Belgaum district in which the majority of the basin area is located (Figure 3). The growth in irrigation infrastructure (mainly tubewells and canals in the command area of reservoirs) resulted in an increase of net cropped area by about 41 per cent. The expansion of agriculture was mainly to the marginal lands, such as barren, that were not cultivated till then. This 
transformation in agriculture manifested in improved soil moisture that enormously helped to combat the adverse effect of drought in this area.

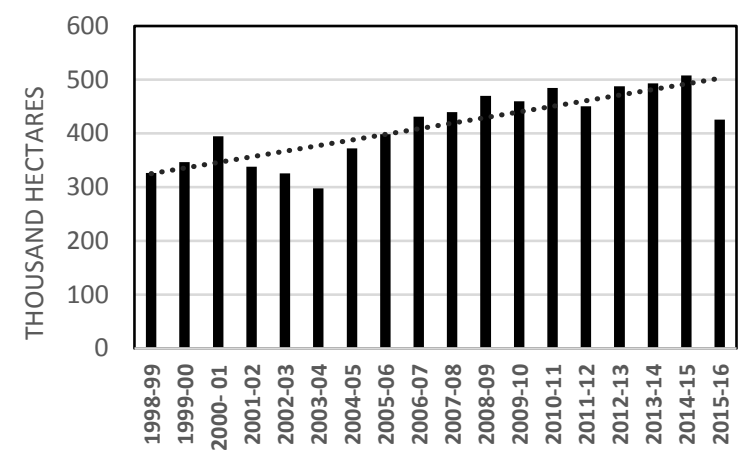

Figure 3. Growth in net irrigated area in Belgaum district of Karnataka

\subsection{Agriculture Drought Assessment.}

3.3.1 Crop and Vegetation Status: The crop conditions have shown significant variations across the Malaprabha sub-basin under different intensities of drought (Figure 4). The VCI is showing extremely low values in the waterbody region, which is completely an uncomplimentary region for vegetation. Other low VCI values are found in the regions of barren land and fallow land, showing that these regions are devoid of vegetation.

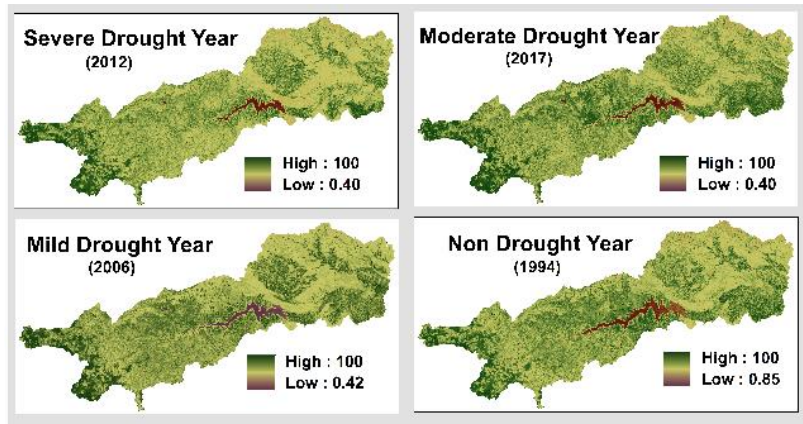

Figure 4. Variation in vegetation conditions index under different drought intensity and non-drought conditions.

These areas are mainly located in the north-eastern and eastern part of the basin where the moisture status is very low owing to the adverse pedological conditions. The extremely high and high VCI values are observed in the regions of forest and agriculture land with irrigation facilities, showing the optimum vegetation condition. There was higher variation in VCI values within the agriculture areas because of the variations in the soil moisture conditions. The variations in soil moisture stem from the differences in irrigation water availability or non-availability as well as source and frequency of irrigation during different periods of cropping seasons. In addition, rainfall distribution pattern in the months prior to the image acquisition also determined the variations in VCI values. In years that experienced different intensities of drought, the VCI values were found to be lower and of wide range. In contrast, the non-drought year had relatively higher lower bound VCI values. It is also to be noticed that higher VCI values are always in the vicinity of water bodies or along the command areas of reservoirs and other water harvesting structures.
3.3.2 Temperature Stress on Vegetation: The regions with low TCI values are representing the most favorable condition for drought while high TCI value regions designate unfavorable drought condition. In severe and moderate drought years, more pixels came under the range of low TCI values compared to mild and non-drought years. This wide range of lower TCI values specifies the areas that are under the impact of thermal-stress. The northern and north-eastern regions of the watershed had low TCI values, suggestive of higher drought intensities (Figure 5). These areas, in general, have steeper slopes, exposed soils and least moisture holding capacity. The non-drought year was showing maximum pixels in the range of higher TCI values demonstrating least moisture stress conditions. During different drought intensity years, the southeast and south-central regions of the sub-basin were under low TCI (mild to severe drought) conditions. These areas were under high TCI value during the non-drought year, showing the presence of vegetation during that time.

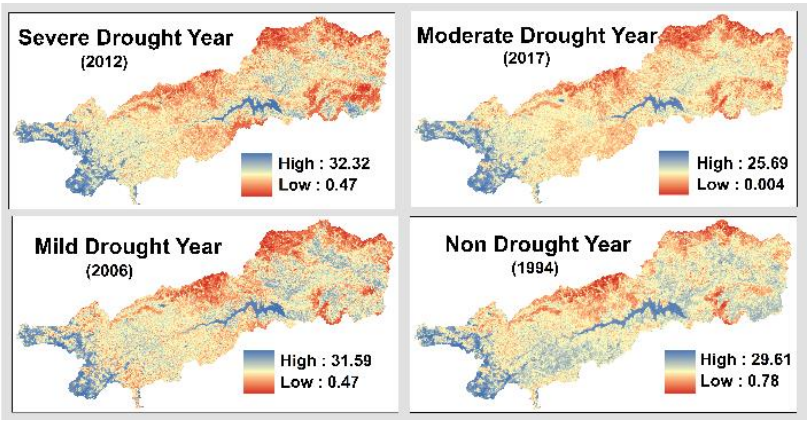

Figure 5. Variation in temperature conditions index during different drought intensity and non-drought conditions.

3.3.3 Agricultural Drought: The impact of meteorological drought on agriculture was analyzed through VHI, which was estimated by integrating the indices VCI and TCI. The VHI point to the overall vegetation health. The areas having lower $(<40)$ VHI values are prone to drought. During the analysis years, the study area is mainly showing moderate to mild agriculture drought conditions, while severe drought condition is observed only in very small portions (Figure 6). Even in the year of severe meteorological drought, the impact on agriculture was relative less since the majority of the sub-basin experienced only moderate to mild agricultural drought. The severe agriculture drought area is confined to higher elevation along the catchment boundary in the northeast where either the soil thickness is less or the area has exposed lateritic soil.
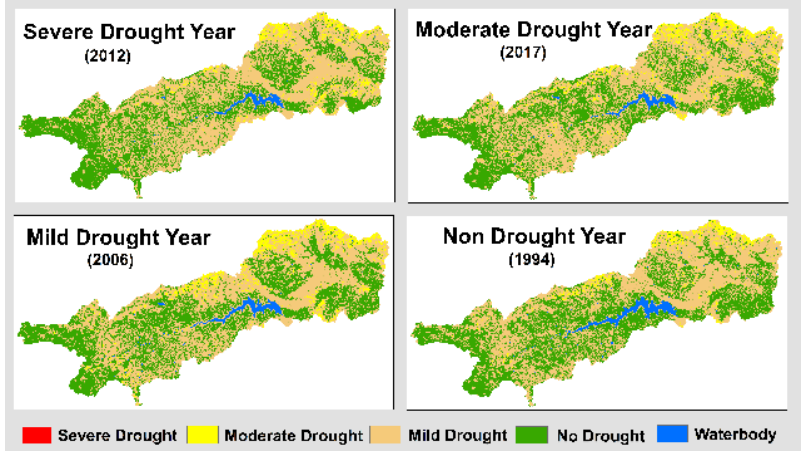

Figure 6. Drought intensity classes and non-drought conditions.

The extreme agricultural drought condition was not observed in any of the study years, showing the reasonable vegetation and 
moisture constancy in the study area. During different drought intensity years, considered (as per SPI values) in this study, the shift in the area mainly occurred among moderate, mild, and nondrought areas. As we transit from severe drought to non-drought year, the non-drought areas are significantly increasing while drought areas are decreasing (Table 3). Simultaneously, there was a progressive increase in the submerged area of water harvesting structures from the drought to non-drought years. Among the drought classes, the change is mainly happening in the moderate drought areas which are shifting either to mild or non-drought areas depending upon the degree of rainfall deficiency, especially during the post-monsoon season. The impact of meteorological drought and its manifestation in agricultural areas depends upon soil moisture conditions, which is contingent upon whether irrigation water is locally available in the area or not. It also depends on whether the deficiency in rainfall occurs during the agricultural season or not. The postmonsoon rainfall deficiency has greater soil moisture stress, and the following agriculture season gets severely affected by the drought.

Table 3. Area under non-drought, drought and water bodies (in sq.km)

\begin{tabular}{lcccc}
\hline Classes & $\begin{array}{c}\text { Severe } \\
\text { Drought } \\
(2012)\end{array}$ & $\begin{array}{c}\text { Moderate } \\
\text { Drought } \\
(2017)\end{array}$ & $\begin{array}{c}\text { Mild } \\
\text { Drought } \\
(2006)\end{array}$ & $\begin{array}{c}\text { Non- } \\
\text { Drought } \\
(1994)\end{array}$ \\
\hline $\begin{array}{l}\text { Non } \\
\text { drought }\end{array}$ & 1446.80 & 1448.67 & 1538.57 & 1584.75 \\
$\begin{array}{l}\text { Drought } \\
\text { Water }\end{array}$ & 2221.07 & 2211.52 & 2109.25 & 2036.96 \\
Spread & 51.37 & 59.05 & 71.42 & 97.52 \\
\hline
\end{tabular}

Another important land cover change observed during the span of study years between 1994 and 2017 is the increase in the number of artificial water bodies. Since 1994 many decentralized water harvesting structures, as well as irrigation infrastructures (Figure 3), were constructed in this sub-basin. These infrastructures were instrumental in offsetting the impacts of meteorological droughts on agriculture in the study area. Along with variations in different agriculture drought classes, large scale variations in the water spread area is also observed in various drought and non-drought years. An analysis, based on NDWI, showed lesser water extent in drought years as compared to non-drought years. The areas of lateritic exposure in the subbasin consistently showed drought conditions irrespective drought and non-drought years. This is primarily due to the low moisture retention capacity of these soils to support vegetation/crop growth. Thus it can be concluded that the effect of meteorological drought on agriculture is contingent upon many factors such as the distribution of the pattern of rainfall, antecedent soil moisture conditions, and availability of irrigation infrastructure. With variation in time, spatial variation within different drought classes is also seen due to the alteration in the intensity of the different climatic factors governing the vegetation health. The increase in irrigation facilities over time, especially after the year2000, in the sub-basin lessened the impact of meteorological drought on agriculture even during the severe conditions.

\section{CONCLUSIONS}

The study attempted to analyze the agriculture drought in the Malaprabha sub-basin. There were widespread drought conditions in this area. The occurrence and intensity of drought varied over time and space. The agricultural drought conditions closely associated with the meteorological drought experienced in the basin. However, the impact of meteorological drought conditions on agriculture reduced over time in the sub-basin due to the widespread increase in irrigation facilities. The increase in surface irrigation and extraction of groundwater significantly not only reduced the intensity of the impact of droughts on agriculture but also resulted in declining spatial extent. In the earlier periods of study, the agricultural droughts were more conditioned by the distribution pattern of rainfall. If the postmonsoon rainfall was around the normal or above, then the chances of widespread agriculture drought was less. On the other hand, if the post-monsoon rainfall is below normal, invariably, the agricultural drought intensity and spatial occurrence were higher. In contrast, in recent times the effect of severe meteorological drought in the sub-basin was less due to the increase in irrigation water security in the area from the surface and underground sources. The spatial variations in the intensity of agricultural drought was conditioned by the degree of exposure of the land surface to solar radiation. Areas of lateritic exposure are still more prone to agriculture drought since their water retention capacity is less.

The results of this study indicate the usefulness of the satellite image-based indices such as TCI, VCI, and VHI for agrometeorological drought assessment and its effective spatial monitoring. In addition, these indices are also beneficial in concurrent assessment and diagnosis of the impact of soil water deficiency and effect of high atmospheric temperature on the phenology of crops and other vegetation and in turn agriculture drought assessment, its intensity, and spatio-temporal variations.

The area-specific long term historical drought information and their effect on agriculture is not available in developing and less developed countries. The satellite-based agricultural drought indices are very useful for historical analysis of the characteristics of droughts and their effects on soil moisture, agricultural crops, and even the natural vegetation. The historical agriculture drought information is also useful for insurance companies to make an informed decision on designing appropriate area specific insurance products and also to verify the crop damage/loss claims of the farmers.

\section{ACKNOWLEDGEMENTS}

Authors acknowledge the United States Geological Survey (USGS) Earth Resources Observation and Science (EROS) Centre for providing access to archives of the Landsat Thematic Mapper (level 1 and level 2) satellite images and India Meteorological Department for the rainfall data.

\section{REFERENCES}

Basso, B., Cammarano D., and Vita P. D., 2004. Remotely sensed Vegetation Indices: Theory and Applications for Crop Management. Rivista Italiana di Agrometeorologia, 53(1), pp. $36-53$.

Bento , V. A., .Gouveia, C. M., DaCamara, C.C., Trigo, I. F., 2018. A climatological assessment of drought impact on vegetation health index. Agricultural and Forest Meteorology. 259(15), pp. 286-295.

Bhalme, H.N., Mooley, D.A., 1980. Large-scale droughts/floods and monsoon circulation. Monthly Weather Review, 108, $1197-$ 1211. 
Census of India., 2011. District Census Handbook, Belgaum, Village and Town Directory, Series-3-, Part XII-A. Directorate of Census Operations, Karnataka.

CGWB., 2007. Ground water information booklet, Belgaum district, Karnataka. Government of India, Ministry of water resources.

Chander,G., Markham, B. L., and Helder, D. L., 2009.Summary of current radiometric calibration coefficients for landsat MSS, TM, ETM+, and EO-1 ALI sensors. Remote Sensing of Environment, 113(5), pp. 893-903. http://dx.doi.org/10.1016/j.rse.2009.01.007.

Gouveia, C., Trigo, R.M., Beguería, S., Vicente-Serrano, S.M., 2017. Drought impacts on vegetation activity in the Mediterranean region: an assessment using remote sensing data and multi-scale drought indicators. Global and Planetary Change, 151, 15-27. http://dx.doi.org/10.1016/j.gloplacha.2016.06.011

India Meteorological Department., undated. Drought monitoring. http://www.imdpune.gov.in/hydrology/Drought_Monitoring.ht $\mathrm{ml}$

Kogan, F.N., 1987: Vegetation index for areal analysis of crop conditions. Proc. 18th Conf. on Agricultural and Forest Meteorology, West Lafayette, IN, American Meteorological Society, 103-107.

Kogan, F.N., 1994. Application of vegetation index and brightness temperature for drought detection. Advances in Space Research, 15(11), pp. 91-100

Kogan, F.N., 1997. Global drought watch from space. Bulletin of the American Meteorological Society, 78(4), 621-636.

Kogan F.N., 2001. Operational space technology for global vegetation assessment. Bulletin of the American Meteorological Society, 82(9), pp. 1949-64.

Kogan F.N., 2002. World droughts in the new millennium from AVHRR-based vegetation health indices principles of a new algorithm. EOS TRANSACTIONS, 83(48), pp. 3-7.

Mallya, G., Mishra, V., Niyogi, D., Tripathi, S., Rao, S. G., 2015. Trends and variability of droughts over the indian monsoon region. Weather and Climate Extremes, 12, pp. 43-68. http://dx.doi.org/10.1016/j.wace.2016.01.002.

Masek, J.G., Vermote E.F., Saleous,N.E., Wolfe, R., Hall, F.G., Huemmrich, K.F., Gao, F., Kutler, K., Lim T. K., 2006. A landsat surface reflectance dataset, 1990-2000. IEEE Geoscience and Remote Sensing Letters, 3(1), pp. 68-72.

McKee, T.B., Doesken, N.J., Kleist, J., 1993. The relationship of drought frequency and duration to time scales. Proceedings of the Eighth Conference on Applied Climatology, Anaheim, CA. American Meteorological Society (Boston), pp.179-84.

Mishra, A. K., Singh, V.P., 2010. A review of drought concepts. Journal of Hydrology, 391(1-2), pp. 202-16.

Moran, M. S., Clarke, T. R., Inoue, Y., Vidal, A., 1994. Estimating crop water deficit using the relation between surfaceair temperature and spectral vegetation index. Remote Sensing of Environment, 49(3), pp. 246-63.Palmer, W.C., 1965.
Meteorologic Drought. US Department of Commerce, Weather Bureau, Research Paper No. 45, p. 58.

Rojas, O., Vrieling, A., Rembold, F., 2011 Assessing drought probability for agricultural areas in Africa with coarse resolution remote sensing imagery. Remote Sensing of Environment 115(2), pp.343-352.

Sandholt, I., Rasmussen, K., Andersen, J., 2002. A simple interpretation of the surface temperature / vegetation index space for assessment of surface moisture status. Remote Sensing of Environment, 79, pp. 213-24.

Sholihah, R. I., Trisasongko, B.H., Shiddiqa, D., Iman, L. O. S., Kusdaryantoa, S., Manijo, Panuju, D. R., 2016. Identification of agricultural drought extent based on vegetation health indices of landsat data: case of subang and karawang, indonesia. Procedia Environmental Sciences, 33, pp. 14-20.

Singh, R. P., Roy, S., Kogan, F., 2003. Vegetation and temperature condition indices from NOAA AVHRR data for drought monitoring over india. International Journal of Remote Sensing, 24(22), pp. 4393-4402.

Sobrino, J. A., Jiménez-Muñoz, J. C., Sòria, G., Romaguera , M., Guanter, L., Moreno, J., Plaza, A., Martínez, P., 2008. Land surface emissivity retrieval from different VNIR and TIR sensors. IEEE Transactions on Geoscience and Remote Sensing, 46(2), pp. 316-27.

Svoboda, M., Hayes, M., Wood, D., 2012. Standardized Precipitation Index User Guide. World Meteorological Organization, Geneva, Switzerland, Tech. Rep. WMO-No.1090.

Vicente-Serrano, S.M., Beguería, S., and López-Moreno, J.I. 2010. A multiscalar drought index sensitive to global warming: The standardized precipitation evapotranspiration index. Journal of Climatology, 23 (7): 1696-1718. doi:10.1175/2009JCLI2909.1

Vicente-Serrano, S.M., Cabello, D., Tomás-Burguera, M., Martín-Hernández, N., Beguería, S., Azorin-Molina, C., Kenawy, A.El, 2015. Drought variability and land degradation in semiarid regions: assessment using remote sensing data and drought indices (1982-2011). Remote Sensing, 7, 4391-4423. http://dx.doi.org/10.3390/rs70404391.

Vyas, S.S., Bhattacharya, B.K., Nigam, R., Guhathakurta, P. Ghosh, K., Chattopadhyay,N., Gairola, R., 2015. A combined deficit index for regional agricultural drought assessment over semi-arid tract of India using geostationary meteorological satellite data. International Journal of Geographical Information Science, 39, 28-39.

Wang, S., Zhang, L., Huang, C., Qiao, N., 2017. An NDVI-based vegetation phenology is improved to be more consistent with photosynthesis dynamics through applying a light use efficiency model over boreal high-latitude forests. Remote Sensing, 9(7). doi:10.3390/rs9070695

Waseem, M., Ajmal, M., Lee, J. H., Kim, T. W., 2016. Multivariate drought assessment considering the antecedent drought conditions. Water Resources Management, 30(12), pp. 4221-31. http://dx.doi.org/10.1007/s11269-016-1416-5.

WMO., 2018. WMO confirms 2017 among the three warmest years on record. Press Release Number:18-01-2018 
https://public.wmo.int/en/media/press-release/wmo-confirms-

2017-among-three-warmest-years-record.

Zargar, A., Sadiq, R., Naser, R., Khan, F. I., 2011. A review of drought indices. Environmental Reviews, 19, pp. 333-49. 